\title{
El paradigma de la lucidez en la narrativa de Julio Cortázar
}

\author{
Laureano Ralón ${ }^{1}$
}

Resumen. El presente artículo es la continuación necesaria de una indagación previa sobre la temática de la autenticidad en la narrativa de Julio Cortázar. "A todo o nada: el problema de la (in)autenticidad en Rayuela” (Ralón 2014) propuso una exégesis inicial en torno a la búsqueda individual de Horacio Oliveira, en el marco de la filosofía ontológico-existencial de Martin Heidegger. Este artículo propone ampliar dicho análisis a través de una comparación sistemática con dos de sus más notables predecesores: Johnny Carter y Persio. La especulación subyacente es que las búsquedas fallidas, “a todo o nada”, de los perseguidores cortazarianos ocurren en el interior de un mismo paradigma lúcido que representa la sistematización de un tipo de epistemología reduccionista. El fracaso individual de los protagonistas -que a pesar de la diversidad de sus técnicas y tácticas no logran trascender el subjetivismo radical y el individualismo metodológico propiciados por la modernidad, desembocando invariablemente en un solipsismo nihilista- es un componente necesario de un proceso de apertura existencial que comienza con "El perseguidor" (1959), continúa en Los premios (1960) y finaliza en Rayuela (1963).

Palabras clave: ontología; existencialismo; autenticidad; Heidegger; Cortázar.

\section{[en] The paradigm of lucidity in the narrative of Julio Cortázar}

\begin{abstract}
The present article is the necessary follow-up of a previous inquiry on the topic of authenticity in the narrative of Julio Cortázar. “A todo o nada: el problem de la (in)autenticidad en Rayuela” (Ralón, 2014) put forth an initial exegesis centered on the individual search of Horacio Oliveira in the context of Martin Heidegger's existential-ontological philosophy. This article seeks to broaden that analysis by way of a systematic comparison with two of his most notable predecessors: Johnny Carter and Persio. The underlining assumption is that the failed, "all or nothing" explorations of Cortázar's pursuers occur within a lucid paradigm which represents the systematization of a reduccionist epistemology. The individual failures of the protagonists - who despite their diversity of their techniques and tactics are unable to transcend the radical subjectivism and methodological individualism upheld by modernity, ending up invariably in a nihilistic solipsism - is a necessary component in a more general process of existential opening that begins with "The Pursuer" (1959), continues in The Winners (1960) and finalizes in Hopscotch (1963).
\end{abstract}

Keywords: Ontology; Existentialism; Authenticity; Heidegger; Cortázar.

Sumario. 1 Introducción. 2. Desarrollo. 3. Más allá de la lucidez.

Cómo citar: Ralón, L. (2018) The paradigm of lucidity in the narrative of Julio Cortázar, en Anales de Literatura Hispanoamericana 47, 455-471.

1 Universidad Michoacana de San Nicolás de Hidalgo, Morelia. México.

E-mail: ralonlaureano@gmail.com 
"Si la lucidez desemboca en la inacción, ¿no se vuelve sospechosa, no encubre una forma particularmente diabólica de ceguera?” - Horacio Oliveira

\section{Introducción}

En “A Todo o Nada: el problema de la (in)autenticidad en Rayuela” (Ralón 2014), argumentamos que la denuncia perpetua de la inautenticidad por vía del absurdo (sea trágico o humorístico) no es condición suficiente de posibilidad de una existencia auténtica en un sentido ontológico-existencial estricto, es decir, un compromiso resuelto de cara a la finitud que por primera vez se revela en el serpara-la-muerte [Sein zum Tode], pero que requiere fundamentalmente de una proyección genuina hacia posibilidades futuras que emanan de la irreemplazabilidad de cada Dasein, esto es, su centro existencial indelegable. Dado el carácter no-positivo y no-evaluativo del fenómeno de la (in)autenticidad en Heidegger (1997: 258), argumentamos también que es erróneo equiparar el comportamiento de Horacio Oliveira con una pulsión de tipo hedonista (Pinheiro Machado 2005), y concluimos que sus infortunios son consecuencia de una disposición errática y reduccionista: un híbrido entre escepticismo hipercrítico y absurdo humorístico que todo lo problematiza y todo deforma. No obstante, la hipótesis subyacente a nuestra investigación es que las búsquedas "a todo o nada"

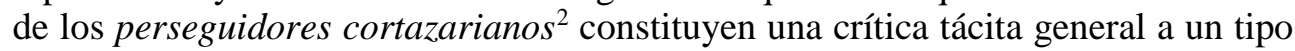
de epistemología fundada en el subjetivismo radical y el individualismo metodológico propiciados por filosofía moderna.

El objetivo del presente artículo es ampliar nuestra indagación contextualizando la búsqueda personal de Oliveira a través de una contrastación sistemática con dos de sus más notables predecesores (Johnny Carter y Persio), a fin de entablar una línea crítica de continuidad en el rechazo cortazariano a la epistemología citada. Como lo señaló en más de una oportunidad el propio Cortázar, Rayuela significa la clausura de un proceso de negación sistemática de la realidad cotidiana y de admisión de otras posibles aperturas. Nuestra hipótesis de trabajo es que dicho proceso se inicia con "El perseguidor" (1959), se extiende a Los premios (1960) y desemboca en Rayuela (1963) como "un camino que pretende encontrar la autenticidad del hombre” (Alba 2000: 247). Creemos que este proceso se produce a expensas de los "fracasos" individuales de los perseguidores, cuyas búsquedas fallidas trascurren en el interior de una misma estructura, la cual, siguiendo a García Canclini (1968) y en sintonía con Heidegger, denominamos paradigma de la lucidez. En este sentido, las búsquedas fallidas de los personajes serán tomadas aquí como fracasos necesarios en un proceso general de apertura existencial que se desarrolla a lo largo de los textos citados. Respecto de esta paradoja que constituye

2 Saúl Sosnowski (1983), en su entrevista con Julio Cortázar, propone el término «perseguidores» (en plural) para referirse entre otros a Johnny Carter y Oliveira. Sosnowski observa que en la narrativa cortazariana «siempre hay un personaje que busca, que persigue algo» En este ensayo utilizaremos el término «perseguidores» en el sentido que le asigna Sosnowski para referirnos puntualmente a Johnny Carter, Persio y Horacio Oliveira. 
el nodo central de nuestra tesis, las siguientes palabras de Cortázar cobran un sentido revelador: "Rayuela prueba cómo mucho de esa búsqueda puede terminar en fracaso, en la medida en que no se puede dejar así no más de ser occidental...” (Harss 1968: 269).

Más concretamente, nuestro trabajo gravitará en torno a los siguientes supuestos: 1) que cada personaje se sitúa de manera idiosincrática en el interior del paradigma lúcido; 2) que cada una de estas localizaciones primarias se corresponde con una disposición vital y con una constitución ontológica específicas; 3) que a pesar de su diversidad metodológica, los perseguidores no logran superar los confines de lo lúcido, desembocando invariablemente en el callejón sin salida del solipsismo nihilista; 4) que el fracaso de Rayuela representa el cierre del período existencial en la narrativa cortazariana, preparando el camino para una lógica de tipo impersonal (post-humanista) cuyo principal exponente es 62/Modelo para armar..

\section{Desarrollo}

Antes de abocarnos a un análisis de las localizaciones primarias de los personajes mediante una fenomenología de sus disposiciones vitales, es necesario definir la noción de lucidez — eje central de nuestra investigación- con el fin de situar nuestra indagación en un plano estrictamente filosófico. En Julio Cortázar, una antropología poética (1968), García Canclini introduce el término "lucidez” para describir la actitud inconformista e hipercrítica de Oliveira, un intelectual que desmenuza sus observaciones y cada uno de sus actos para tejer las consecuencias últimas de la persecución. En una sección clave del texto titulada, "los riesgos de la lucidez”, el crítico argentino ofrece la siguiente caracterización del protagonista de Rayuela:

Oliveira no puede dejar de ser inteligente, no puede contemplar las cosas y estar tranquilo junto a ellas sin definirlas con una frase brillante. Es el drama del racionalismo occidental, del hombre occidental: luego de haber puesto distancia entre el sujeto y el objeto no le es posible dejar de mirarlo, no halla la manera de reincorporarse a la realidad...Las catástrofes de Oliveira son causadas por su obstinado propósito de ser lúcido...Horacio es un intelectual paralítico, exiliado de muchas cosas pero sobre todo de la acción...Esa "lucidez hipercrítica” lo sustrae de cualquier tarea que arriesgue su independencia, tanto en los problemas colectivos como en las relaciones personales (García Canclini 1968: 46-49).

El diagnóstico de García Canclini acerca de la psicología y el comportamiento de Oliveira es acertado. Sin embargo, sus apreciaciones se limitan a consideraciones óntico-existentivas que se manifiestan en el plano vivencial y anímico inmediato del sujeto. En líneas generales, tanto la antropología poética de García Canclini como el trabajo antropológico-filosófico de otros autores en torno a la temática de la (in)autenticidad en Cortázar (Curutchet 1972, Genover 1978, Osorio 2002, Pinheiro Machado 2005) parecen inspirados en el existencialismo de Jean-Paul Sartre más que en la ontología-existencial de Martin Heidegger. En el 
siguiente párrafo, Carlos Astrada explica la diferencia fundamental entre el pensamiento de ambos filósofos:

...es el caso que a Heidegger no se lo puede incluir entre los "existencialistas", palabra ambigua, que aquí hace referencia a los contenidos ónticos del Dasein, tal como éstos son vividos anímicamente, y cuya descripción es, sin duda, necesaria; mas esta descripción es, en Heidegger, simplemente un medio para un fin. Un filósofo que se limita únicamente a esta descripción no es existencial, sino existentivo. De modo que siguiendo la falsa opinión de expositores y críticos de Heidegger, lo que se llama 'existencialismo' debe designarse, para evitar confusiones, con el nombre apropiado de 'existentivismo'. Heidegger, en este sentido, no es existencialista. Ya en la Introducción de Sein und Zeit hace la estricta distinción entre existenziell, lo óntico relativo al Dasein, y existencial, lo relativo a la estructura ontológica de la Existenz (existencialidad) (1970: 20).

En efecto, los intérpretes de la (in)autenticidad en Cortázar con frecuencia pecan de no realizar el trabajo propedéutico necesario —una analítica de los determinantes ontológico-existenciarios del estar-en-el-mundo - para brindar una exégesis más completa de las disposiciones vitales, localizaciones primarias y constituciones ontológicas específicas de los personajes. Como ya hemos argumentado (Ralón 2014), sus aportes se circunscriben a un existencialismocomo-existentivismo que desestima las estructuras fundamentales de la existencia y que es incapaz de descubrir el ser de los fenómenos en toda su complejidad. El resultado de este enfoque es la vinculación arbitraria de la (in)autenticidad con el hedonismo (Pinheiro Machado 2005), con el absurdo (García Canclini 1968) o con la náusea (Curutchet 1972: 43). Por el contrario, lo auténtico en su concepción heideggeriana estricta no es algo óntico-factico u orgánico-material, sino la proyección hacia posibilidades futuras a partir del eje existencial insustituible de cada Dasein. En Ser y el tiempo (1997), Heidegger aclara que la muerte como posibilidad máxima e ineludible y como punto de partida para una existencia auténtica no posee un contenido positivo o evaluativo específico:

La muerte, como posibilidad, no le presenta al Dasein ninguna 'cosa por realizar’, ni nada que él mismo pudiera ser en cuanto real. Por su misma esencia, esta posibilidad no ofrece ningún asidero para una espera impaciente de algo, para 'imaginarse en vivos colores' lo real posible, y olvidar de esta manera su posibilidad (258).

El propio Cortázar parece ser consciente de este principio ontológico básico cuando, por boca de su alter-ego Morelli, afirma en Rayuela que "el hombre no es, sino que busca ser, proyecta ser” (286). Esta peculiar insinuación, sumada al corto alcance de los análisis ónticos ya citados, nos motivan a proponer un abordaje ontológico más estricto para la problemática de la (in)autenticidad en la narrativa cortazariana. En lugar del existencialismo sartreano, que a simple vista puede resultar una elección mucho más lógica dado el contexto histórico y las influencias inmediatas del escritor argentino (Cortázar 1949), optamos aquí por una perspectiva ontológico-existencial de corte heideggeriano. La elección es ante todo 
metodológica: lo que buscamos es profundizar el análisis de nuestros predecesores y avanzar hacia consideraciones de tipo estructural (existenciarias).

En relación al fenómeno de lo lúcido, García Canclini se contenta con asociarlo ónticamente al "racionalismo occidental" (46); esto le impide ver que, pese a sus diferencias metodológicas, los personajes llevan adelante sus búsquedas en el interior de una misma estructura. Nuestra interpretación, en cambio, propone una dimensión histórica, esto es, línea de continuidad que atraviesa la tríada "El Perseguidor"-Los premios-Rayuela, en un esfuerzo sistemático y diacrónico por demarcar los límites de la lucidez a expensas de los fracasos individuales de los perseguidores. Como veremos, la saturación de este paradigma culmina en una lógica de corte post-humanista que se manifiesta cabalmente en 62/Modelo para armar, la novela impersonal de Morelli.

Ahora bien, ¿a qué nos referimos cuando hablamos de lucidez? En vez de confinar este fenómeno a una definición explícita, optemos por delimitarlo invocando sus condiciones mínimas de posibilidad. En primer lugar, aunque la lucidez suele instrumentarse de manera lógica y racional, creemos que su potencial metodológico no se agota en una contemplación teórica que todo lo desmenuza por la vía analítica. Como veremos, Johnny Carter es alguien que comúnmente definiríamos como un ser intuitivo, carente de distanciamiento racional: "La verdadera explicación”, dice el protagonista de "El perseguidor” (Cortázar 1959), "no se puede explicar" (588). Sin embargo, esta intuición no-racional —una suerte de instinto ciego - en última instancia no logra trascender los confines de lo lúcido, pues, en rigor, responde a una disposición vital que no deja de ser crítica y reduccionista. Curutchet (1972) afirma en relación con “Las armas secretas” que "podría ser considerado como un intento de situar la irracionalidad en el seno de lo real, o mejor aún, de revelar la esencia irracional de lo real” (53). No obstante, el problema con el "racionalismo" y el "irracionalismo" es que conforman dos caras de la misma moneda metafísica moderna: dos categorías que resultan inadecuadas a la hora de comprender las disposiciones vitales de los perseguidores y sus localizaciones primarias en el interior del paradigma lúcido. Nuestra posición, en cambio, es que la lucidez como sistematización de una epistemología reduccionista fundada en el subjetivismo radical y el individualismo metodológico excede por completo la dicotomía “racional-irracional”. La lucidez, en todo caso, denota un tipo de búsqueda: se trata de una variación escéptica del estar-en-el-mundo que podemos denominar “crítica” en la medida en que reduce la realidad humana a algo más acá o más allá de la experiencia vivida, culminando indefectiblemente en un solipsismo nihilista. En este contexto, las siguientes palabras de Oliveira cobran un sentido casi profético: "si la lucidez desembocaba en la inacción”, se pregunta el protagonista de Rayuela, “¿no se volvía sospechosa, no encubre una forma particularmente diabólica de ceguera?” (Cortázar 1963: 37-38).

Otra manera de avanzar en la demarcación del paradigma lúcido es vincularlo con lo que Heidegger denomina la "metafísica de la presencia” y contrastarlo con lo que el propio Cortázar llama “el sentimiento de no estar del todo”. Por metafísica de la presencia, Heidegger se refiere a una suerte de logocentrismo que concibe al ser en su presencia-presente, y cuya aproximación al mundo de la vida no alcanza a develar la realidad humana en toda su complejidad. Como señala 
Josep María Bech (2001), la metafísica tradicional ha reducido el tratamiento del ser en función del modo temporal del presente:

La metafísica considera, efectivamente, que el ser irrumpe de manera omnipresente con el mismo talante disponible de los entes subsistentes, o sea que atribuye al ser el carácter supremamente óntico que Heidegger denomina Vorhandenheit. Y justifica su predilección por el presente temporal haciendo prevalecer su propio confinamiento en el ámbito de lo subsistente y de lo disponible... Presente y presencia, en suma, se legitiman recíprocamente el rango preponderante que les asigna la metafísica (193).

Para contrarrestar este avance metafísico y su empecinado énfasis en la presencia, Heidegger (1977) recurre a una radicalización existencial de la fenomenología trascendental husserliana, argumentando que el ser del fenómeno no se agota en su mero aparecer ante la conciencia. Para ello, hace hincapié en los distintos modos de manifestación fenoménica, como el encubrimiento o el disimulo:

\begin{abstract}
¿A qué se debe llamar “fenómeno” en un sentido eminente? ¿Qué es lo que por esencia necesariamente debe ser tema de una mostración explícita? Evidentemente, aquello que de un modo inmediato y regular precisamente no se muestra, aquello que queda oculto en lo que inmediata y regularmente se muestra, pero que al mismo tiempo es algo que pertenece esencialmente a lo que inmediata y regularmente se muestra, hasta el punto de constituir su sentido y fundamento. Ahora bien, aquello que eminentemente permanece oculto o recae de nuevo en el encubrimiento, o sólo se muestra "disimulado", no es este o aquel ente, sino, como lo han mostrado las consideraciones anteriores, el ser del ente (44).
\end{abstract}

Para nuestro propósito, la noción heideggeriana de encubrimiento como contraconcepto del fenómeno - es decir, su remisión a un trasfondo de inteligibilidad como sostén de una realidad objetiva - servirá como una indicación formal de los confines del paradigma lúcido. Al modelo sujeto-objeto que propone una concepción del ser humano como ente racional, Heidegger contrapone la noción del Dasein como "proyecto arrojado" [geworfener Entwurf] que se interpreta a sí mismo. De este modo, el paradigma lúcido basado en la percepción y el conocimiento empírico como correlatos de una realidad objetiva da lugar a un paradigma hermenéutico centrado en la interpretación situada, encarnada y finita en un mundo público y referencialmente estructurado como "contexto remisional de la significatividad” (1997: 127).

Creemos que esta noción de un mundo irreductible a una presencia objetiva es afín a lo que Cortázar llama "el sentimiento de no estar del todo". De hecho, en un ensayo de título homónimo (2005), el escritor define este sentimiento como "una participación parcial en mi circunstancia" (262). Sin embargo, esta "participación parcial" no debe confundirse con el distanciamiento racional que con frecuencia acompaña a la lucidez, mucho menos con la "medianidad" [Durchschnittlichkeit] que caracteriza a la interpretación pública del “uno” [das Man]; está más bien 
vinculada con una suerte de “extrañamiento” que tampoco es sinónimo de “alienación” en el sentido peyorativo del término [Entfremdung]. Asimismo, la asociación de la lucidez con el extrañamiento no presupone una relación de causalidad necesaria: el extrañamiento no es síntoma de una patología a tratar, sino indicio de la inviabilidad de lo lúcido como proyecto totalizador de una epistemología reduccionista; es ante todo un señalamiento de los límites del autoconocimiento y de la accesibilidad a los objetos del mundo, que con frecuencia se substraen de nuestra aprehensión consciente para ocultarse en un trasfondo subterráneo que no es el mundo platónico de las formas, sino parte integral de una mundicidad multiestable. En el siguiente párrafo, Cortázar describe su “sentimiento" en profundidad:

Ese sentimiento, que creo se refleja en la mayoría de mis cuentos, podríamos calificarlo de extrañamiento... en cualquier momento que podemos calificar de prosaico, en la cama, en el ómnibus, bajo la ducha, hablando, caminando o leyendo, hay como pequeños paréntesis en esa realidad y es por ahí, donde una sensibilidad preparada a ese tipo de experiencias siente la presencia de algo diferente, siente, en otras palabras, lo que podemos llamar lo fantástico... ese sentimiento, ese extrañamiento, está ahí, a cada paso, vuelvo a decirlo, en cualquier momento y consiste sobre todo en el hecho de que las pautas de la lógica, de la causalidad del tiempo, del espacio, todo lo que nuestra inteligencia acepta desde Aristóteles como inamovible, seguro y tranquilizado se ve bruscamente sacudido, como conmovido, por una especie de, de viento interior, que los desplaza y que los hace cambiar (270).

En síntesis, creemos que el sentimiento de “no estar del todo” y la "búsqueda intersticial” se presentan en la narrativa cortazariana como reacción y alternativa a la lucidez al remitirnos a un trasfondo de inteligibilidad que posibilita el surgimiento de otras posibles aperturas en el "mundo circundante" [Umwelt].

Sobre esto último, Curutchet (1972) observa que "el tema de las realidades paralelas había sido tratado por primera vez en 'Lejana', uno de los cuentos de Bestiario. Pero allí era todavía una especie de hipótesis de trabajo, uno de los mecanismos para suscitar lo fantástico, como los espíritus de 'Casa tomada”” (42). Agrega que, en "Las armas secretas”, “el Pont Neuf y Enghien están ya fundidos en una nueva dimensión de la realidad que progresivamente se ha instalado en el seno de la cotidianidad... La verificación de la irracionalidad en el seno de lo real provoca el quiebre de un racionalismo vulgar” (42). La noción de realidades paralelas propuesta por Curutchet, aunque viciada de un cierto bagaje metafísico dualista, parece superar provisionalmente la tendencia excesivamente óntica de algunos intérpretes (García Canclini 1968/1982, Genover 1978, Osorio 2002, Pinheiro Machado 2005), quienes suelen confundir la existencia inauténtica con la modalidad indiferenciada del Dasein en la cotidianidad [Indifferenz]. Como veremos, este equívoco conduce a un problema recurrente: la comprensión de la inautenticidad como una forma de alienación que es consecuencia directa de la mecanización y la monotonía diarias. Como señala Carman (2005), la relación entre inautenticidad y alienación deriva del discurso romántico de una autorealización expresiva que se remonta a Rousseau, Herder y Goethe e incluye a 
figuras del siglo xix como Hegel, Marx y Dilthey (287). Estos pensadores "expresivistas" conciben al ser como una conquista personal, en contraste con distintos tipos de condiciones deficientes, como la alienación, la aislación, la fragmentación y la incoherencia. En este sentido, dicha conquista significa alcanzar una suerte de totalidad o integralidad; sin embargo, el ideal de la auto-realización es, según Carman, inalcanzable para el Dasein, cuyo modo de ser es la existencia (sus posibilidades).

La lectura romántica de la (in)autenticidad, a la que suscriben la mayor parte de los intérpretes cortazarianos que se han abocado a esta temática, suele traducirse en un enfoque que contempla al escritor como un destructor de la cotidianidad. Luis Harss, por ejemplo, afirma que el propósito de la literatura cortazariana es "derrumbar barreras para dar acceso a un orden de la realidad que está del otro lado de la experiencia cotidiana" (1968: 270). Para García Canclini (1968), Cortázar "insta a cultivar lo azaroso, lo excepcional, a rebelarnos contra lo dado e instaurar la creación", porque "las excepciones ayudan a salvarnos, y nosotros debemos ayudar a las excepciones rebelándonos contra los hábitos” (69). Olga Osorio (2002), por su parte, argumenta que Rayuela es "un intento de abrir los ojos a la realidad auténtica, a aquella que existe al margen del mundo creado por la cultura y la historia humanas" (15). Asimismo, Pinheiro Machado (2005) observa que la autenticidad en Cortázar se establece a través de la trascendencia de la realidad cotidiana: "El 'kibbutz del deseo' cortazariano", afirma, "representa una especie de más allá, un ámbito utópico que contradice la noción heideggeriana de autenticidad como alcanzable solamente en el aquí y el ahora del ser-en-el-mundo" (114). Ahora bien, estas afirmaciones no se consustancian con declaraciones del propio Cortázar, para quien la "maravilla" en lo cotidiano que moviliza, por ejemplo, a Oliveira, no es trascendente, sino "profundamente humana":

El problema central para el personaje de Rayuela...es que él tiene una visión que podríamos llamar maravillosa de la realidad. Maravillosa en el sentido de que él cree que la realidad cotidiana enmascara una segunda realidad que no es ni misteriosa, ni trascendente, ni teológica, sino que es profundamente humana, pero que por una serie de equivocaciones ha quedado como enmascarada detrás de una realidad prefabricada con muchos años de cultura, una cultura en la que hay maravillas pero también profundas aberraciones, profundas tergiversaciones. Para el personaje de Rayuela habría que proceder por bruscas interrupciones en una realidad más auténtica (cit. en Osorio 2002: 18).

Algo que ignoran los intérpretes cortazarianos es que, pese al fracaso de los perseguidores, la negación sistemática de la realidad cotidiana como función de una apertura existencial no significa la aniquilación de lo cotidiano, sino un encuentro con lo fácticamente dado que conduce a la descompresión de posibilidades latentes en la mundicidad.

Respecto de esto último, hay que tener en cuenta que el principio general de figura-fondo — proveniente de la psicología gestáltica por vía de la fenomenología trascendental de Edmund Husserl - es compatible con el principio de multiestabilidad; es además un recurso central en la narrativa cortazariana, muy ligado al "sentimiento de no estar del todo" y a la noción de "búsqueda 
intersticial”. En entrevista con Luis Harss (1968), Cortázar utiliza términos como "figuras” y "estructuras” para describir una suerte de "superficie nítida y cristalina” que oculta "fuerzas opacas que llevan a una silenciosa catarsis en la que hay a la vez alivio y desbordamiento" (271-272). Es evidente que el carácter multiestable de la relación entre figura y fondo guarda una estrecha relación con el "sentimiento" y la "búsqueda intersticial” como vías de escape del paradigma lúcido. Sin embargo, quienes ven en Cortázar a un destructor de la cotidianidad tienden a adoptar una lógica maniquea que equipara la inautenticidad con la existencia indiferenciada, anónima y enajenante de la cotidianidad. Esta asociación no es del todo injustificada. Por momentos, el propio Heidegger (1997) parece trazar una distinción muy fuerte entre cotidianidad y autenticidad:

El sí-mismo del Dasein cotidiano es el uno-mismo [Man selbst], que nosotros distinguimos del sí-mismo propio, es decir, del sí-mismo asumido expresamente. En cuanto uno-mismo, cada Dasein está disperso en el uno y debe llegar a encontrarse. Esta dispersión caracteriza al "sujeto" de ese modo de ser que llamamos la absorción ocupada en el mundo que comparece inmediatamente (129).

Asimismo nos dice que "en la cotidianidad del Dasein la mayor parte de las cosas son hechas por alguien de quien tenemos que decir que no fue nadie" (131). Sin embargo, Heidegger también aclara que "el modo propio de ser-sí-mismo no consiste en un estado excepcional de un sujeto, desprendido del uno, sino que es una modificación existentiva del uno entendido como un existencial esencial" (134). Afirma además que la cotidianidad no es en sí misma sinónimo de primitividad en el sentido de un plano superficialmente mundano que es necesario trascender:

La interpretación del Dasein en su cotidianidad no se identifica empero con la descripción de una fase primitiva del Dasein, cuyo conocimiento pueda ser proporcionado empíricamente por la antropología. Cotidianidad no coincide con primitividad. Por el contrario, la cotidianidad es un modo de ser del Dasein que éste tiene incluso y precisamente cuando se mueve en una cultura altamente desarrollada y diferenciada (59).

En definitiva, la existencia indiferenciada de la cotidianidad no es para Heidegger una modalidad deficiente, sino parte integral de la mundicidad, de cuya modificación existentiva emergen tanto la existencia auténtica como la inauténtica.

Con lo expuesto hasta aquí debería quedar claro que la inautenticidad no deriva de la cotidianidad como un especio lógico-objetivo perfectamente determinado, sino de la apropiación y proyección acrítica de posibilidades inauténticas, es decir, socialmente mediatizadas por interpretación pública del "uno". Del mismo modo, no alcanzamos la autenticidad "rebelándonos contra los hábitos" o en la "renuncia sistemática al compromiso" (García Canclini 1968: 62-69), sino a través de un proyecto resuelto que se apropie de las posibilidades del mundo circundante. En este sentido, parecen inadecuadas las lecturas de "El perseguidor" (1959), Los premios (1960) o Rayuela (1963) en términos de una crítica a la modalidad 
existencial indiferenciada de la cotidianidad niveladora. Por el contrario, los textos citados conforman en su conjunto un rechazo general del paradigma lúcido como sistematización de una epistemología reduccionista asociada con la "metafísica de la presencia”.

Enfoquémonos ahora en las localizaciones primarias de los perseguidores cortazarianos en el interior de lo lúcido. Como afirmamos desde el comienzo, la lucidez se manifiesta en los perseguidores a través de disposiciones vitales específicas: desde la intuición miope desprovista de racionalidad que le brinde coherencia (Johnny), hasta la actitud contemplativa y teórica de un ego solitario y desencarnado (Persio), o la síntesis de lo anterior en un híbrido que combina escepticismo hipercrítico con absurdo humorístico (Oliveira). Por separado, las metodologías de los perseguidores varían de forma considerable en función de sus inquietudes y motivaciones; sin embargo, estas variaciones emanan fundamentalmente de las distintas localizaciones en el paradigma lúcido.

Las localizaciones primarias de los perseguidores, tal como se manifiestan en sus disposiciones vitales, conforman los límites estructurales/paradigmáticos de la lucidez. Ahora bien, pese a estar contenidos por el mismo paradigma, Persio y Johnny se ubican en extremos opuestos de un mismo continuo, mientras que Oliveira encarna una especie de síntesis que, en última instancia, no resulta superadora. Como veremos más adelante, la existencia plena —el no estar del todo cortazariano como señalamiento de una realidad intersticial y ampliada — requiere de una localización que no se substraiga del mundo (Persio), pero que tampoco se funda acríticamente con él (Johnny) ni quede a mitad de camino entre la tierra y el cielo (Oliveira). Por lo pronto, al extremo más racional, contemplativo y teórico del espectro tenemos a Persio, personaje que para la antropología poética de García Canclini representa un misterio: “... este astrólogo retórico se cae de cualquier clasificación”, admite. "Como personaje se halla poco definido, y su función lateral está bien representada por los monólogos en bastardilla que interrumpen el relato" (1968: 41). Desde una perspectiva fenomenológica, la disposición de este perseguidor es claramente reflexiva y su localización en el interior de lo lúcido encarna una suerte de perspectiva anónima; de hecho, su visión totalizadora es lo más parecido a una óptica científica, o a la mirada de Dios. Al respecto, Cortázar dijo alguna vez que "Persio es la visión metafísica de esa realidad corriente" y que "ve las cosas desde lo alto como las ven las gaviotas" en "una especie de visión total y unificadora" (Harss, 1968: 277). Este tipo de visión desde ningún lugar se corresponde con la constitución ontológica de un ser desencarnado, la cual se manifiesta en su incapacidad de intervenir en su circunstancia de manera directa. Harss (1968) escribe que “lo que desvirtúa un poco la ‘visión metafísica' de Persio es que parece tener algo de cirugía estética. Más que ampliar las perspectivas, fija la escena, imponiendo un orden casi puramente formal” (278).

En efecto, la metodología de Persio consiste en colorear la experiencia vivida, sepultándola bajo una cartografía simbólica para brindarle una inteligibilidad derivada. Desde esta óptica, la siguiente apreciación de García Canclini (1968) cobra un sentido revelador:

[Para Persio] la realidad no se deja explicar plenamente. El hombre sólo cuenta con los símbolos -el ferrocarril, la guitarra y la tercera mano-, torpes analogías 
pero únicas esperanzas de que el caos no sea el caos sino la distorsión de una forma que se nos escapa. Los símbolos son las confidencias de lo trascendente, los recursos para penetrar en su sentido, caminos hacia ese "punto central donde cada elemento discordante puede llegar a ser visto como un rayo de la rueda" (142).

Una vez más, Persio es lo más parecido a una pantalla que proyecta coordenadas complejas sobre el mundo para bridarle un sentido extrínseco. Al respecto, es interesante releer las apreciaciones de García Canclini en clave de esta lectura:

[Para Persio] sería preciso ver simultáneamente lo que ven los cuatro mil millones de ojos de la raza humana, construir un mapa de lo viviente. Para ensayarlo, se entretiene con la Guía oficial dos caminos de ferro de Portugal, traza los itinerarios de todos los trenes que recorren el territorio a una misma hora seguro de producir un diagrama que sea más que la suma de los recorridos, que revele el destino último de sus ocupantes (141).

Naturalmente, esta perspectiva privilegiada no garantiza el acceso al "kibutz cortazariano" ni a la autenticidad heideggeriana, pues si algo nos enseña la fenomenología es que la experiencia vivida no puede ser reducida a un agregado de símbolos, por sugestivos que sean. En última instancia, la tentativa de Persio fracasa porque deforma el mundo de la vida y lo sepulta bajo una suerte de mapa simbólico. Pero lo más curioso de Persio es lo ambiguo de su proceder: por un lado, afirma que el Malcolm es una jaula en la que los muñecos son movidos por leyes que desconocen y los determinan trágicamente, es decir, que concibe la situación en el barco en términos reduccionistas; por otro, busca exorcizar esta situación determinista recurriendo a una maniobra que barre la experiencia vivida bajo un manto de simbolismos.

García Canclini (1968) ofrece una interesante taxonomía de los personajes de Los premios (1960), la cual puede resultarnos útil para comprender mejor la localización primaria de Persio en el paradigma de lo lúcido. Para el crítico argentino, esta categorización tripartita está ligada a la actitud que los personajes asumen hacia la popa, aunque a mi forma de ver parece inspirada por la noción heideggeriana descubrimiento y descubrimiento del ser del fenómeno. Según Heidegger (1997), el modo en que pueden estar encubiertos los fenómenos es múltiple:

En primer lugar, un fenómeno puede estar encubierto en el sentido de que aún no ha sido descubierto. No se lo conoce ni se lo ignora. En segundo lugar, un fenómeno puede estar recubierto. Y esto quiere decir: alguna vez estuvo descubierto, pero ha vuelto a caer en el encubrimiento. Este encubrimiento puede llegar a ser total, pero regularmente ocurre que lo que antes estuvo descubierto todavía resulta visible, aunque sólo como apariencia. Pero, cuánto hay de apariencia, tanto hay de "ser”. Este encubrimiento, en el sentido del “disimulo", es el más frecuente y el más peligroso, porque las posibilidades de engaño y desviación son aquí particularmente tenaces (45). 
Para García Canclini (1968), el primer grupo lo conforman los que "se han instalado en lo inmediato y jamás cuestionan sus condicionamientos ni se preguntan por el sentido último de la existencia” (39), grupo que se corresponde con el encubrimiento heideggeriano. El segundo grupo lo constituyen "quienes alguna vez entrevieron una dimensión diferente, pero se quedaron más acá de la búsqueda” (39-49), categoría que supone un descubrimiento recubierto. Por último, están quienes logran "encontrarse con lo mejor de sí en el examen de conciencia que la soledad del barco hacen posible", es decir, "los que acceden a la autenticidad” (40). Persio, no obstante, representa un desafío de clasificación en la medida en que se presenta como una alternativa a los demás personajes, los auténticos como los inauténticos. Según García Canclini, Persio no es un perseguidor, sino un oráculo. No obstante, pese a su constitución desencarnada, él también persigue algo y su proyecto totalizador es de hecho uno de los más ambiciosos. Para nuestro propósito, se trata de una manifestación extrema de la lucidez y de un tipo de búsqueda que le impide comprometerse con su circunstancia más allá de la contemplación teórica y distante.

$\mathrm{Al}$ otro extremo del mismo continuo encontramos a Johnny Carter, protagonista de "El perseguidor" (1959). Uno de los epígrafes del cuento sugiere que Johnny es un idealista ("sé fiel hasta la muerte") y a simple vista diríamos que "está en las nubes”. Para Harss (1968),

[Johnny] es una pobre alma perdida, ignorante de sus propias facultades, que vive atormentándose con sus percepciones, sin comprenderlas. Capta indicios de un infinito que desconoce y no puede retener. Es una visión informe, una nebulosa que al final lo pierde. El camino lleva cuesta abajo, a través de las drogas, a la locura (273).

García Canclini (1968), por su parte, asocia el fracaso del perseguidor a la falta de distanciamiento racional: "Si [Johnny] finalmente y se pierde es porque vive atormentándose con sus intuiciones sin ser capaz de pensarlas en una visión coherente” (44). Una vez más, este tipo de descripciones no constituyen una caracterización existencial suficiente, pues la psicología y comportamiento de los personajes son el producto de disposiciones vitales y constituciones ontológicas más básicas. Desde una perspectiva fenomenológica, Johnny es quién más tiene los pies sobre la tierra en el sentido de estar fundido con su mundo. En el siguiente párrafo, su amigo y biógrafo Bruno da cuentas de la modalidad absorbida que caracteriza a Johnny y su estar-en-el-mundo:

Dan ganas de decir en seguida que Johnny es como un ángel entre los hombres, hasta que una elemental honradez obliga a tragarse la frase, a darla bonitamente vuelta, y a reconocer que quizá lo que pasa es que Johnny es un hombre entre los ángeles, una realidad entre las irrealidades que somos todos nosotros (44).

El problema reside principalmente en su localización en la estructura lúcida tal como se manifiesta en su tendencia a reducir la experiencia vivida a través de una "permanente rebelión contra las exigencias de lo cotidiano" (Curutchet 1972: 45). 
Como ya hemos señalado, lo cotidiano como modalidad existencial indiferenciada no es en sí mismo sinónimo de inautenticidad, sino trasfondo de posibilidad tanto de la existencia auténtica como de la inauténtica. En este sentido, su escéptica rebelión contra lo cotidiano — sumada al solipsístico "viaje interior" — conducen a Johnny al nihilismo: pese a su gran sensibilidad, es incapaz de proyectarse hacia posibilidades auténticas de manera coherente y fundada. Johnny muere siendo fiel a un ideal, a su música, a un estilo de vida; pero su naturaleza fragmentaria -la dispersión de su ser en la búsqueda insaciable del inconformista — sugiere que no es fiel a sí mismo en un sentido ontológico-existencial.

En efecto, una constante de los perseguidores cortazarianos es que sus disposiciones reductivas les impiden asumir resueltamente la investidura de ese eje existencial indelegable que les devela la angustia y el ser-para-la-muerte, condición necesaria de posibilidad de una proyección auténtica más allá de la opresión de un presente inmediato. En relación con Los premios, Curutchet (1960) afirma que

...el presente absolutizado -el presente ininterrumpido de los personajes; el tiempo circular del Malcolm - está ligado aquí con la ausencia de una experiencia integrada de la vida o con las dificultades para integrar esa experiencia. La absolutazación del presente deviene correlativa de la mutilación del ser (59).

Para García Canclini (1968), "la insuficiencia presente deja de abrumarnos al decidir, como Johnny, que 'la realidad o puede ser esto"” (110); sin embargo, a pesar de sus vagas intuiciones, Johnny es incapaz de trascender más allá del ahora. Por momentos parece tomar conciencia del significado de su existencia (en declaraciones como "esto lo estoy tocando mañana" falta referencia parece haber una comprensión pre-ontológica de la existencia como un arrojo-proyectado), pero es incapaz de fundar sus perspicacias en un proyecto resuelto que le brinde un sentido al mañana. El resultado, pese a su gran sensibilidad, es un solipsismo que le impide relacionarse saludablemente con otros y hasta consigo mismo.

En el caso de Oliveira presenciamos un final ambiguo e incierto, alguien que va por la vida a los tumbos y queda a mitad de camino entre el cielo y la tierra de su Rayuela. El crítico dijo alguna vez que "El perseguidor" era una Rayuelita; el propio Cortázar se mostró de acuerdo con esta interpretación, e incluso confesó que fue en "El perseguidor" donde dejó de sentirse cómodo. En entrevista con Saúl Sosnowski (1983), declara:

Yo creo que 'El perseguidor' es el momento -del que yo no tenía conciencia clara, sin embargo; eso lo veo ahora a distancia - en que... comencé a salir de una actitud que tal vez se podría calificar de demasiado egoísta... y empecé a mirar un poco más allá de lo que lo había hecho hasta ese momento.

Sin duda, Johnny puede ser tomado como un prototipo de Oliveira, pero la búsqueda de este último consiste por sobre todo en "subvertir categorías lógicas y esquemas racionales, en bracear contra todos los molinos del sufragio universal, perdiendo pie hasta desembocar en una última razón de la sinrazón quijotesca que es a la vez un pantano y un trampolín” (Harss 1968: 180). Esta caracterización deja entrever un desgarramiento en Oliveira, quien procura una comprensión racional 
pero al mismo tiempo trata inútilmente de negarla porque descubre que el racionalismo es un estorbo. Hay sin duda un avance en relación con Persio, que según Cortázar, "ve las cosas desde lo alto como las ven las gaviotas” (cit. en Harss 1968: 277). De hecho, al analizar los personajes desde el horizonte de significación de nuestra línea de continuidad entre "El perseguidor" (1959), Los premios (1960) y Rayuela (1963), Oliveira parece emerger dialécticamente de una síntesis entre Johnny y Persio. El polo racional y analítico de Persio se funde con el polo irracional e intuitivo de Johnny para dar lugar al híbrido radicalizado, cuya combinación entre el escepticismo hipercrítico y absurdo humorístico significa la clausura de un proceso que demarca los límites del paradigma lúcido para su posterior rechazo. Para Harss (1968), Oliveira es un "insatisfecho crónico que a fuerza de sofismas estériles, paradojas fáciles y falsas autocríticas se ha arrinconado en la incapacidad de encontrar una razón de vivir o de hacer nada" (280). Una vez más, el problema es más profundo y atañe al irracionalismo como alternativa del racionalismo, el cual no logra liberarse del todo de los prejuicios de la metafísica moderna. Lo que sucede, como sentencia Heidegger en su Carta sobre el humanismo (2000), es que la inversión de un postulado metafísico no deja de ser un postulado metafísico. Racional o irracionalmente, Oliveira comparte con Persio y Johnny la misma tendencia crítica que violenta y reduce el mundo de la vida a algo más acá o más allá de la experiencia vivida, y esta reducción del mundo trae como correlato una reducción del ser.

\section{Más allá de la lucidez}

Recapitulemos nuestros argumentos hasta aquí. El giro existencial que conduce a Cortázar a transitar "un camino que pretende encontrar la autenticidad del hombre" (Alba 2000: 247) se desarrolla a expensas de los personajes individuales, cuyas búsquedas fallidas constituyen fracasos necesarios en un proceso general de apertura ontológica: Johnny muere, el destino de Oliveira es incierto y Persio es incapaz de intervenir de manera directa en su circunstancia. Como la revolución que devora a sus hijos, el fracaso de los perseguidores parece una constante que atraviesa los textos analizados. Como hemos visto, las disposiciones y metodologías de los personajes varían de manera significativa: desde la contemplación teórica y desencarnada que proyecta símbolos sobre la experiencia vivida para otorgarle un significado extrínseco, pasando por la intuición desprovista de distanciamiento racional que se funde con el mundo, hasta llegar a una suerte de híbrido hipercrítico que todo lo problematiza por vía analítica y al absurdo humorístico. Sin embargo, a pesar de estas variaciones, sus localizaciones primarias se fundan en el interior de una misma estructura que, inspirados en la noción de metafísica de la presencia, denominamos paradigma de la lucidez. En última instancia, tanto Persio como Johnny y Oliveira son seres fragmentados que no logran encontrar su centro; su existencia se encuentra fracturada entre la miopía de un presente, el solipsismo de la aventura interior y vagas intuiciones sobre un futuro distante y difuso. Parte del problema es que todos los personajes se localizan más acá de la experiencia, limitados por el individualismo metodológico de un subjetivismo solipsista, es decir, colocados atomísticamente en el instante presente. 
El ensimismamiento solipsístico que sufren los perseguidores de la lucidez implica una tendencia a violentar la experiencia vivida desde las anteojeras de su existencia claustrofóbica. El resultado es una rebelión estéril contra las costumbres, los hábitos, la rutina y todo lo que consideran "cotidiano". Desconocen que la cotidianidad es parte del trasfondo de inteligibilidad de una mundicidad multiestable, de cuya modificación existentiva emergen tanto la existencia auténtica como la inauténtica. El auténtico estar-en-el-mundo es un aquí-allí, un proyecto-arrojado. En última instancia, la autenticidad necesita de un estado de resolución [Entschlossenheit], es decir, de apertura y proyección que es todo lo contrario al solipsismo de un subjetivismo lúcido. Por el contrario, Oliveira, Johnny y Persio se empeñan por igual en violentar la experiencia vivida por distintas vías: del escepticismo hipercrítico al absurdo humorístico, de la superimposición de símbolos a la intuición irracional y miope.

A expensas del fracaso de los personajes, sin embargo, la línea de continuidad que conecta "El perseguidor" (1959) con Los premios (1960) y con Rayuela (1963) devela los límites de la lucidez: la incapacidad de alcanzar la autenticidad desde un subjetivismo individual radical. Una hipótesis plausible es que el proceso de apertura existencial -a saber, el rechazo al paradigma lúcido como sistematización de un tipo de epistemología reduccionista centrada en el modelo sujeto-objeto - son un paso obligado hacia el descubrimiento del otro que quedará plasmado en textos como "Reunión” y "Libro de Manuel”. En palabras de García Canclini (1968), "para librarse del subjetivismo...cada individuo cuenta con los otros; sólo se puede superar el solipsismo realizando la existencia solidariamente" (110). Sin embargo, nos interesa cerrar este artículo destacando un momento singular que se desarrolla entre el período existencialista y el descubrimiento del prójimo al que hace alusión Canclini, el cual no ha sido estudiado a fondo por la crítica. Me refiero al período inaugurado por 62/Modelo para armar y, en menor medida, los textos lúdicos que anteceden y preceden a dicha novela (La vuelta al día en ochenta mundos, Último Round y algunos cuentos de Todos los Fuegos, el Fuego). En particular, 62/MPA ha sido uno de los textos menos comprendidos y más combatidos de toda la producción cortazariana, el cual, paradójicamente, marca el momento en el que el paradigma de la lucidez se ve superado por una lógica de tipo impersonal (post-humanista). Se trata de un período breve que pronto se verá opacado por las demandas históricas y por el papel que Cortázar asume como intelectual comprometido, sobre todo a partir de la publicación de "Libro de Manuel”. Dada la extensión de este ensayo, sólo podemos aludir a esta línea de fuga de manera tangencial.

En un artículo reciente analizamos en detalle la recepción crítica de 62 (Ralón 2016). Ante la imposibilidad de extraer un mensaje coherente de las entrañas del texto, esta novela disruptiva fue concebida por la crítica como un esquema cerrado carente de sentido. En consecuencia, fue sepultada bajo una serie de estructuras totalizadoras y/o trascendentes que le brindan una inteligibilidad derivada: o está construida como un calidoscopio (Alazraki 1981), o es una permutación de reflejos y duplicaciones (Serra Salvat 2010), o subsiste bajo un manto especular ubicuo (Lobo 2012), o es la manifestación del inconsciente profundo mediante una intencionalidad onírica (Zeppegno 2012). En ningún caso se le permitió a 62 mostrarse por y desde sí misma. El propio Cortázar se permitió dudar de la 
legitimidad de esta obra al concebirla a la sombra de su novela predilecta: "62 se fue por otro camino que no tenía nada que ver con Rayuela", declara en entrevista con Saúl Sosnowski (1983). "Traté de hacer otra cosa y me metí en un mundo muy complicado". Las reservas del autor, sumadas al hermetismo innegable del texto y la reacción mayormente hostil de lectores y críticos, han hecho de 62 una novela conflictiva y rebelde que suscita todo tipo de lecturas reduccionistas. Pero si en términos literarios la novela ostenta un formidable hermetismo, la misma constituye una realidad irreductible y su valor filosófico no debe ser subestimado. En pocas palabras, 62/MPA es el momento en que Cortázar ensaya una transición de una ontología de la identidad a una ontología plana sin jerarquías. Más concretamente, el devenir filosófico del texto supone una transformación de los personajes en singularidades, esto es, elementos expresivos que forman parte de una multiplicidad contingente. Este movimiento implica una suerte de aplanamiento de las manifestaciones más excesivamente egocéntricas de los perseguidores con miras a superar la metáfora organicista que caracteriza el período humanista de la narrativa cortazariana. Más concretamente, 62 es el momento en el que Cortázar se muestra como un constructor de ensamblajes literarios, y la novela en general puede leerse como un ejercicio antiantropocéntrico y post-humanista. Lamentablemente, Cortázar no apostó a reconducir su estilo literario en esta dirección innovadora, lo cual, tal vez, hubiese significado la renovación de su narrativa tras el agotamiento post-Rayuela. La posibilidad de transitar una ontología de multiplicidades (sin jerarquías) que emancipara su prosa de una concepción "humana, demasiado humana” de la literatura, ampliando de paso la noción de lo real y anticipando desde la literatura los lineamientos básicos de una filosofía especulativa, se vio coartada por un renovado proyecto humanista, atravesado por las urgencias de un realismo social y estilizado por una "política del collage" (Orloff 2014: 248). En adelante, toda investigación futura que aspire a redescubrir la narrativa de Cortázar y su relevancia para el siglo XXI debe partir de una superación de la falsa dicotomía entre el período existencial y el período histórico, entre el Cortázar apolítico y el Cortázar comprometido, explorando en cambio áreas marginales de su obra como vía de acceso a una realidad intersticial más profunda, esto es, el substrato diferencial y dramático (múltiple, secreto, informe) sobre el que se monta el mito cortazariano.

\section{Referencias bibliográficas}

Alazraki, Jaime, “62, modelo para armar: novela calidoscopio”, Revista Iberoamericana, XLVII (1981), pp. 155-163

Alba, Horacio, "Rayuela, de Julio Cortázar: la obra literaria como instrumento de investigación filosófica”, Taula, quaderns de pensament, 33-34 (2000), pp. 239-250.

Bech, José María. De Husserl a Heidegger. La transformación del pensamiento fenomenológico. Barcelona: Ediciones Universitarias, 2001.

Cortázar, Julio, "Irracionalismo y eficacia”, Realidad, 6, septiembre-diciembre, (1949), p. 253.

—Las armas secretas. Buenos Aires: Editorial Sudamericana, 1959.

—Los premios. Buenos Aires: Editorial Sudamericana, 1960. 
—Rayuela. Madrid: Cátedra, 1963.

— Julio Cortázar o la crítica de la razón pragmática. Madrid: Editora Nacional, 1972.

- “Del sentimiento de no estar del todo”, en La vuelta al día en ochenta mundos. México: Siglo XXI, 2005.

Escudero-Alie, María Elvira Luna, "Una lectura existencialista de la narrativa del primer Cortázar”, Espéculo, 28 (2004). Disponible en: https://pendientedemigracion.ucm.es/info/especulo/numero28/cortaexi.html

García Canclini, Néstor. Julio Cortázar, una antropología poética. Buenos Aires: Editorial Nova, 1968.

— “La inautenticidad y el absurdo en la narrativa de Cortázar”, Revista de Filosofía, 16 (1982), pp. 65-77.

Genover, Kathleen. Claves de una novelística existencial (en Rayuela de Cortázar). Madrid: Gredos, 1978.

Harss, Luis, “Julio Cortázar, o la cachetada metafísica”, en Los Nuestros. Buenos Aires: Sudamericana, 1968.

Heidegger, Martin. El ser y el tiempo. Trad. de J.E. Rivera. Santiago de Chile: Editorial Universitaria, 1997.

—Carta sobre el humanismo. Trad. de H. Cortés y A. Leyte. Madrid: Alianza Editorial, 2000.

—¿Qué significa pensar? Trad. de R. Gabás. Madrid: Editorial Trotta, 2005.

Lobo, Olga, "62 ese "ovni” cortazariano: perspectivas para una poética hermenéutica de la novela”, Escritural: Ecritures d'Amérique Latine, 5. Disponible en: http://www.mshs.univ-poitiers.fr/crla/contenidos/ESCRITURAL/ ESCRITURAL5/ESCRITURAL_5_SITIO/PAGES/Lobo.html

Orloff, Carolina. La construcción de lo político en Julio Cortázar. Buenos Aires: Ediciones Godot, 2014.

Osorio, Olga, "Entender, no inteligir: sobre Rayuela, de Julio Cortázar”, Espéculo, 21 (2002). Disponible en: https:// pendientedemigracion.ucm.es/info/especulo/numero21/rayuela.html

Ralón, Laureano, "A todo o nada: el problema de la (in)autenticidad en Rayuela", Cuadernos del Centro Interdisciplinario de Literatura Hispanoamericana, 16 (1) (2014).

Sartre, Jean-Paul. Being and Nothingness: An Essay on Phenomenological Ontology. Londres: Routledge, 1969.

Serra Salvat, Rosa, “62 Modelo para armar de Julio Cortázar, entre la experimentación vanguardista y la tradición literaria”. Disponible en: http://www.iiligeorgetown2010.com/2/pdf/Serra-Salvat.pdf

Sosnowski, Saúl, “Entrevista a Julio Cortázar”, en El Juglar. 1983. Disponible en: https://www.youtube.com/watch?v=dmJdZDoj7xk

Zeppegno, Giulliana, “A pesar de Morelli: 62/Modelo para armar de Julio Cortázar entre fi guras y causalidad onírica”, Anales de Literatura Hispanoamericana, 41 (2012), pp. 321-344. 